\title{
Male Sex Hormone affection in patients with Tramadol dependance
}

\author{
Alaa Eldin M. Darweesh, Hossam Khalifa", Romany H. Gabra and Mena M. Fahim
}

\begin{abstract}
Background: Tramadol is a centrally active synthetic opioid analgesic that is used extensively among Egyptian males for premature ejaculation as a self-medication.

The present work conducted to outline male sex hormone affection in patients with tramadol dependence and its relation to sexual satisfaction.

Results: Tramadol-dependent patients have significantly lower mean serum level of testosterone compared to the control group and lower mean Sexual Satisfaction Scale than the control group.

Conclusions: The results provide evidence for the association between male sex hormone suppression in patients with tramadol dependence with high Addiction Severity Index of tramadol dependence.
\end{abstract}

Key words: Dependence, Tramadol, Male sex hormone affection

\section{Background}

Tramadol is a centrally active synthetic opioid analgesic that is used extensively. Its mode of action is not completely understood, but two acceptable complementary mechanisms are binding to mu opioid receptors and inhibition of reuptake of norepinephrine and serotonin [1]. From literature, multiple cases of toxicity and abuse of tramadol have been reported. The main symptoms of tramadol toxicity include central nervous system depression, nausea and vomiting, tachycardia, and seizures. Fatal cases have been reported as a result of tramadol overdose. In those instances, death has been attributed to cardiopulmonary arrest and hepatic failure as well as hypoglycemia [2].

The tramadol oral absorption is more than morphine and bioavaliabity reached to about $95-100 \%$ and absorbed rapidly in the small intestine and reached highest peak after $5 \mathrm{~h}$. It is widely distributed throughout the body, especially liver and kidneys [3].

Follicle-stimulating hormone (FSH) and luteinizing hormone (LH) are gonadotropins. FSH and LH are synthesized and secreted by the gonadotropic cells of the

* Correspondence: hossamkhalifa71@Yahoo.com

Neuropsychiatry Department, Assiut University Hospital, Assiut, Egypt anterior pituitary gland and regulate the development, growth, pubertal maturation, and reproductive processes of the body. FSH and luteinizing hormone (LH) work together in the reproductive system [4].

Testosterone is the primary male sex hormone and an anabolic steroid. In male humans, testosterone plays a key role in the development of male reproductive tissues such as the testes and prostate, as well as promoting secondary sexual characteristics such as increased muscle and bone mass and the growth of body hair and sexual arousal [5].

An increase in some of researches shows a direct effect of tramadol abuse with pituitary release of LH and FSH which thus interferes with the menstrual cycle in women and decrease of the normal pulsatile release of LH leading to a negative effect on the testes of males caused by the decrease of testosterone levels [6].

A reduction in testosterone levels will eventually lead to decrease in sexual drive as well as sustenance of erection. Also, a malfunction in HPG axis can result in large changes in the body such as hypogonadism, sluggish libido, erectile dysfunction for the males, irregular menstrual cycles in females, and possibly infertility in both male and females [7]. 


\section{Aim of study}

The study aims to outline male sex hormone affection in patients with tramadol dependence and its relation to sexual satisfaction and its correlation with Addiction Severity Index.

\section{Methods}

\section{Tramadol-dependent patients}

Twenty-five male patients with pure tramadol dependence for at least 12 months [mean age (SD) $34.09 \pm 7.60$ years, ranging from 18-45 years] were selected randomly from the addiction management unit of the psychiatry department in Assiut University Hospital, Assiut, Egypt. The mean duration of tramadol abuse (SD) was $5.1 \pm$ 4.1 years ranging from $1-10$ years. All patients provided fully informed written consent and the local ethical committee of Assiut University had approved the experimental protocol.

\section{Control subjects}

Twenty-five healthy male volunteers, age- and education-matched, were enrolled as a control group for male sex hormone assessment. They had no history of psychiatric disorders which was confirmed during a psychiatric interview. The mean age of the controls were $34.92 \pm 7.04$ years, ranging from $18-45$ years.

\section{Study overview}

A. Medical history and clinical examination:

- Complete history taking and clinical examination.

- Addiction severity measured by Addiction Severity Index

- Sexual activity measured by Sexual Satisfaction Scale for male

B. Laboratory investigations:

All patients and control group were subjected to the following investigations:

1. Kidney function tests (blood urea and creatinine)

2. Liver function tests (liver enzymes, serum albumin and globulin, and direct and indirect bilirubin)

To exclude chronic and debilitating diseases that may affect sexual functions.
3. Drug screening of urine for 6 groups of substance abuse (opioids, tramadol, amphetamine, cannibanoids, benzodiazepines, and cocaine) to exclude the use of other substances abused

4. Serum level of testosterone, FSH, and LH is measured

\section{Statistical analysis}

SPSS version 16 package was used in this study. MannWhitney non-parametric $U$ tests were used to compare demographic and clinical data between the experimental and the control group. $P$ values of $<0.05$ were considered significant.

\section{Results}

The study includes 25 tramadol-dependent patients that have the mean age of $34.09 \pm 7.60$ years with 25 crossmatched controls with the mean age $34.92 \pm 7.04$ years.

Residence and marital status had insignificant differences between the study and control groups $(P>0.05)$. Ten patients are single and 15 patients are married while 12 controls are single and 13 controls are married (Table $1)$.

\section{Level of testosterone, $\mathrm{FSH}$, and $\mathrm{LH}$ in both groups}

Tramadol-dependent patients have significantly lower testosterone level in comparison to the control group $(622.13 \pm 111.34$ versus $879.22 \pm 97.67 \mathrm{ng} / \mathrm{dl}$, respectively; $P=0.00$ ).

Control group patients have a significantly higher level of FSH and LH than patients with tramadol dependence. The mean of FSH and $\mathrm{LH}$ was $3.67 \pm 0.98$ and $4.87 \pm$ $1.03 \mathrm{ng} / \mathrm{dl}$, respectively, in the control group versus 2.65

Table 1 Mean age in both studied groups

\begin{tabular}{|c|c|c|c|}
\hline Age & $\begin{array}{l}\text { Study group }(\boldsymbol{n}= \\
25)\end{array}$ & $\begin{array}{l}\text { Control group }(\boldsymbol{n}= \\
25)\end{array}$ & $\begin{array}{l}P \\
\text { value }\end{array}$ \\
\hline Mean (years) & $34.09 \pm 7.60$ & $34.92 \pm 7.04$ & 0.70 \\
\hline \multicolumn{4}{|l|}{ Marital status } \\
\hline Single & $10(40 \%)$ & 12 (48\%) & 0.97 \\
\hline Married & 15 (60\%) & $13(52 \%)$ & \\
\hline \multicolumn{4}{|l|}{ Education level } \\
\hline Illiterate & $12(48 \%)$ & 0 & 0.04 \\
\hline $\begin{array}{l}\text { Pre-university } \\
\text { level }\end{array}$ & $10(40 \%)$ & $10(40 \%)$ & \\
\hline $\begin{array}{l}\text { University or } \\
\text { above }\end{array}$ & $3(12 \%)$ & 15 (60\%) & \\
\hline \multicolumn{4}{|l|}{ Residence } \\
\hline Rural & $10(40 \%)$ & $10(40 \%)$ & 0.99 \\
\hline Urban & 15 (60\%) & 15 (60\%) & \\
\hline
\end{tabular}

Date was expressed in the form of mean and SD (compared by Student's $t$ test) or frequency (\%) as appropriate. $P$ value was significant if $<0.05$ 
Table 2 Level of testosterone, FSH, and LH in both groups

\begin{tabular}{llll}
\hline Age & $\begin{array}{l}\text { Study group }(\boldsymbol{n}= \\
\text { 25) }\end{array}$ & $\begin{array}{l}\text { Control group }(\boldsymbol{n}= \\
25)\end{array}$ & $\begin{array}{l}\boldsymbol{P} \\
\text { value }^{*}\end{array}$ \\
\hline $\begin{array}{l}\text { Testosterone } \mathbf{( n g} / \\
\text { dl) }\end{array}$ & $622.13 \pm 111.34$ & $879.22 \pm 97.67$ & $\mathbf{0 . 0 0}$ \\
FSH (ng/dl) & $2.65 \pm 0.44$ & $3.67 \pm 0.98$ & $\mathbf{0 . 0 0}$ \\
LH $(\mathbf{n g} / \mathbf{d l})$ & $2.08 \pm 0.32$ & $4.87 \pm 1.03$ & $\mathbf{0 . 0 0}$ \\
\hline
\end{tabular}

*Student's $t$ test was used and $P$ value was significant if $<0.05$

Data was expressed in the form of mean \pm SD

\pm 0.44 and $2.08 \pm 0.32 \mathrm{ng} / \mathrm{dl}$, respectively, in the study group ( $P=0.00$ for each of them) (Table 2$)$.

\section{Sexual Satisfaction Scale in both groups}

It was noticed that the Sexual Satisfaction Scale was significantly higher in the control group in comparison to the study group $(14.44 \pm 3.97$ versus $9.13 \pm 3.34 ; P=$ 0.00) (Table 3)

\section{Addiction Severity Index and its correlation to sex hormone level and Sexual Satisfaction Scale}

The current study showed that the mean Addiction Severity Index was $17.16 \pm 4.56$ with a range between 5 and 34 .

It was noticed that the testosterone hormone and Sexual Satisfaction Scale had a negatively strong significant correlation with the Addiction Severity Index $(r(P)=$ $0.79(0.00)$ and $-0.8(0.00)$, respectively).

But both LH and FSH had a negatively insignificant correlation with the Addiction Severity Index $(r(P)=$ 0.35 (0.0.32) and - 0.4 (0.44), respectively) (Table 4).

\section{Correlation between Sexual Satisfaction Scale and dose and duration of addiction}

In the current study, mean duration of tramadol addiction was 4 years with a range between 1 and 10 years while median daily dose was $450 \mathrm{mg}$ with a range between 100 and $2250 \mathrm{mg}$ per day (Table 5 and Figs. 1, 2 and 3).

\section{Discussion}

This study was designed to determine male sex hormone affection in patients with tramadol dependence

In this study, the patients group included 25 male patients with tramadol dependence. Five patients (20\%) have serum testosterone level lower than those of the control group. This is in agreement with [8], which

Table 3 Sexual Satisfaction Scale in both groups

\begin{tabular}{llll}
\hline $\begin{array}{l}\text { Sexual Satisfaction } \\
\text { Scale }\end{array}$ & $\begin{array}{l}\text { Study group }(\boldsymbol{n}= \\
25)\end{array}$ & $\begin{array}{l}\text { Control group }\left(\boldsymbol{n}=\begin{array}{l}\boldsymbol{P} \\
25)\end{array}\right. \\
\text { value* }^{*}\end{array}$ \\
\hline Mean ( $\mathbf{\text { SD}})$ & $9.13 \pm 3.34$ & $14.44 \pm 3.97$ & $\mathbf{0 . 0 0}$ \\
\hline
\end{tabular}

*Student's $t$ test was used and $P$ value was significant if $<0.05$

Data was expressed in the form of mean \pm SD
Table 4 Correlation of addition severity with FSH, LH, and testosterone and sexual satisfaction

\begin{tabular}{ll}
\hline Parameters & $\boldsymbol{r}(\boldsymbol{P})$ \\
\hline Testosterone & $-\mathbf{0 . 7 9 ( 0 . 0 0 )}$ \\
FSH & $-0.4(0.44)$ \\
LH & $-0.35(0.32)$ \\
Sexual satisfaction scale & $-\mathbf{0 . 8}(\mathbf{0 . 0 0 )}$ \\
\hline$r$ indicates the strength of the correlation while $P$ indicates the significance of \\
the correlation. $\boldsymbol{P}$ value was significant if $<0.05$
\end{tabular}

reported that opioid-induced androgen deficiency has become one of the most common causes of testosterone deficiency among men in many communities.

Also, 3 patients out of 25 (12\%) have serum FSH and LH levels lower than control. This is also in agreement with [9] in their study of opioid-induced endocrinopathy.

In normal physiologic condition, it is expected that as the level of sex hormones decrease, a negative feedback mechanism should trigger the hypothalamus to increase production of GnRH (FSH and LH).

It is noted in the present study that there is a reduction in sex hormones without an adequate increase in gonadotropins; this is in contrast to [10].

Our results suggest marked central inhibition of the hypothalamic-pituitary-gonadal axis, i.e., the occurrence of significantly reduced testosterone levels during tramadol administration has largely been attributed to the inhibitory action of tramadol on GnRH secretion in the hypothalamus.

In this work, there was statistically significant correlation between the severity of male sex hormone reduction with the duration and high doses of tramadol intake which is also correlated with high addiction severity scale, and this is in agreement with [11] in their study of opioid-induced hypogonadism.

In the present study, the mean value of male sex hormone levels showed statistically significant decrease in patient groups of tramadol dependence when compared to the control group.

Another study done by [12] found symptomatic hypogonadism in male with chronic exposure to opioids.

In the current study, it is noted that low levels in sexual satisfaction scale is correlated with high Addiction Severity Index as these patients have spent most time in searching for tramadol and work more to earn more

Table 5 Dose and duration of addiction the stud group

\begin{tabular}{ll}
\hline & Median (range) \\
\hline Dose per day (mg) & $450(100-2250)$ \\
Duration of addiction (year) & $4(1-10)$ \\
\hline
\end{tabular}

$r$ indicates the strength of the correlation while $P$ indicates the significance of the correlation. $P$ value was significant if $<0.05$ 


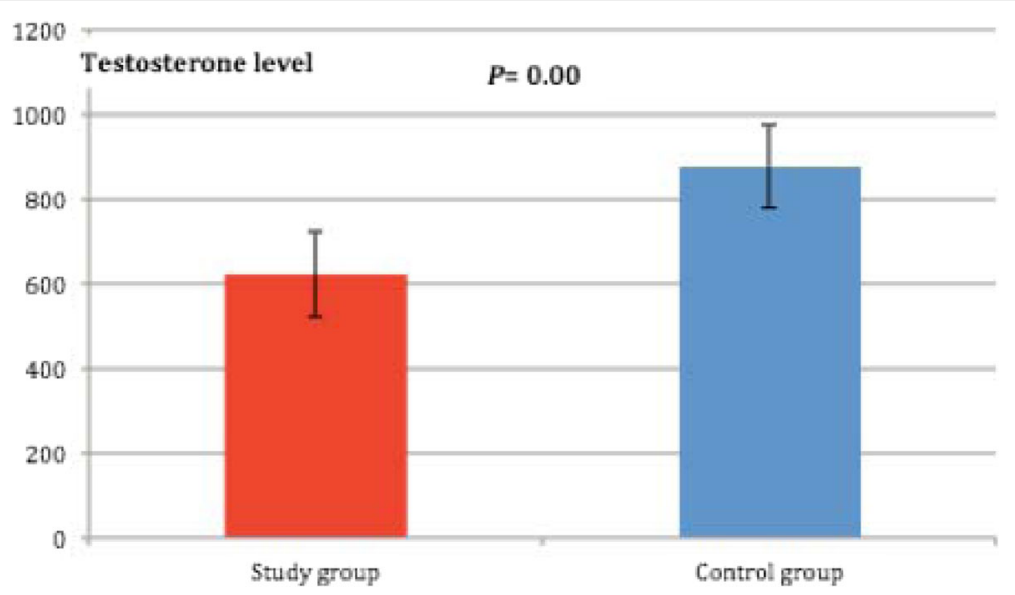

Fig. 1 Level of testosterone in both groups where data was expressed in the form of mean $( \pm S D)$

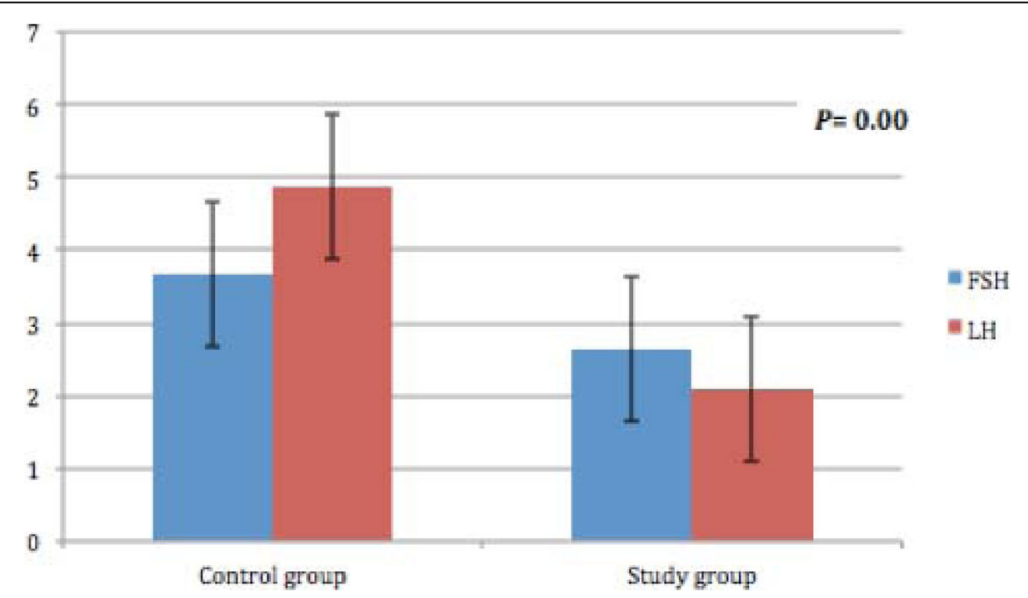

Fig. 2 Level of FSH and LH in both groups where data was expressed in the form of mean ( \pm SD)

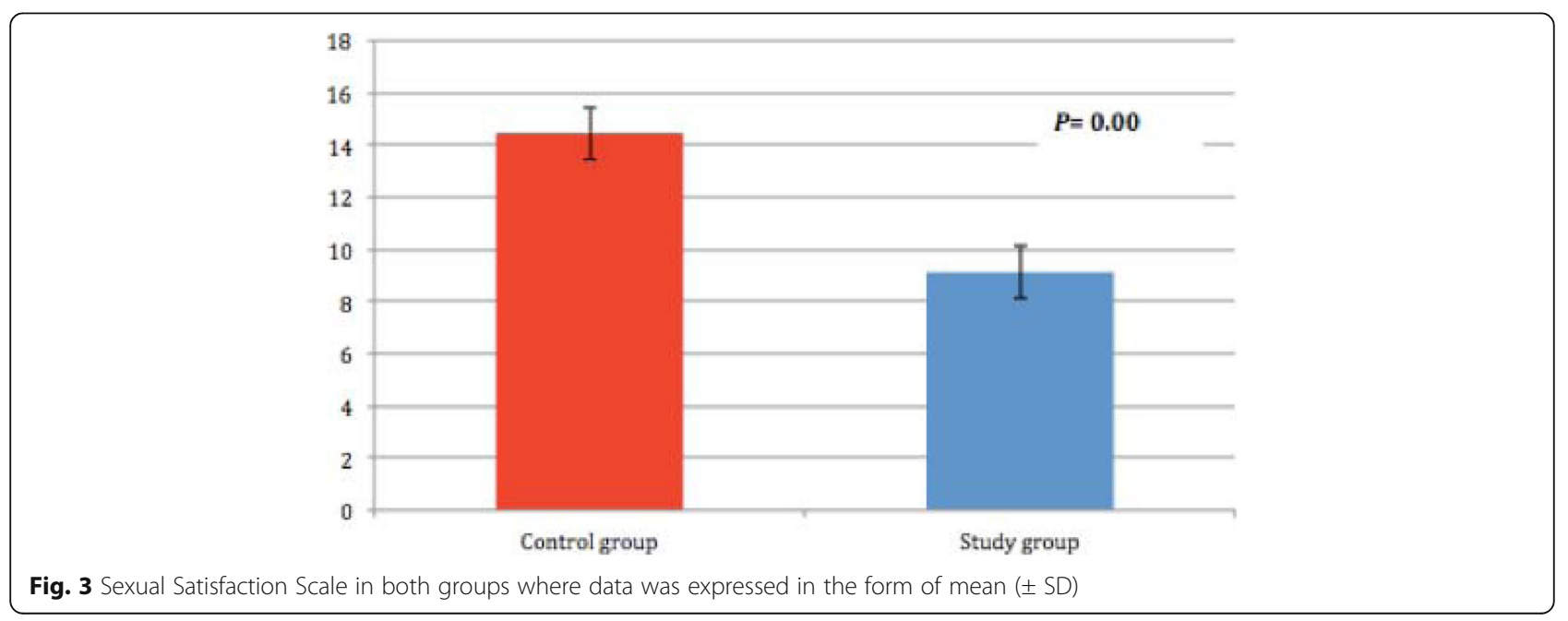


money to buy tramadol so they are not interested in sexual activity with other partners.

Despite that many patients have started tramadol use as a sexual enhancer and as a treatment for premature ejaculation, yet the prolonged use of tramadol decrease sexual capacity that could be attributed to its effect on sex hormones.

\section{Limitations of the study}

Limitations of the study include the following:

1- The relatively small number of patients.

2- The effects of several other comorbidities as the age that is associated with androgen deficiency, also hyperlipidemia, hypertension, and diabetes mellitus, may affect the quality of sexual performance and thus may affect the scores of the Sexual Satisfaction Scale.

Further larger-scale studies are needed to assess the current results.

\section{Conclusion}

The present study found evidence of an association between male sex hormone affection in patients with tramadol dependence with high Addiction Severity Index of tramadol dependence suggesting a direct effect of tramadol on hypothalamic-hypophyseal-gonadal axis.

\section{Abbreviations}

FSH: Follicle-stimulating hormone; LH: Luteinizing hormone;

$\mathrm{GnRH}$ : Gonadotropin-releasing hormone

\section{Acknowledgements}

Not available

\section{Authors' contributions}

AD contributed in the study design, interpretation of the data, and preparing and revising the manuscript. HK contributed in the study design, collected and analyzed, interpreted the data, and prepared the main manuscript. RH contributed in the study design, interpretation of the data, and writing the manuscript. MM contributed in the analysis and interpretation of the data and revising the manuscript. The authors read and approved the final manuscript.

\section{Funding}

The current study was not supported by any national or international institution or organization.

\section{Availability of data and materials}

The datasets generated and/or analyzed during the current study are available from the corresponding author on reasonable request.

\section{Ethics approval and consent to participate}

Before starting data collection, approvals to conduct the study were obtained from the Ethical Review Committee of Assiut Faculty of Medicine and the administrative authority in Neurological and Psychiatric Hospital at Assiut University. Prior to the interview, written informed consent was obtained from the literate participants and was signed in the presence of a witness for illiterate ones. Privacy and secrecy of all data were assured by ensuring the anonymity of the questionnaire, interviewing the participants separately in a closed room and keeping data files in a safe place.
Consent for publication

Not applicable

\section{Competing interests}

The authors declare that they have no competing interests

Received: 23 March 2020 Accepted: 26 March 2020

Published online: 15 May 2020

\section{References}

1. Grond S, Sablotzki A (2004) Clinical pharmacology oftramadol. Clin Pharmacokinet 43:879-923

2. Shadnia S, Soltaninejad K, Heydari K, Sasanian G, Abdollahi M (2008) Tramadol intoxication: a review of 114 cases. Hum ExpToxicol 27(3):201-205.

3. Jellinek $H$, Haumer $H$, Grubhofer $G$, Klappacher, $G$, Jenny $T$, WeindlmayrGoettel M (1990) Tramadol in postoperative pain therapy. Patient-controlled analgesia versus continuous infusion. Anaesthetic 39:513.

4. Jiang X, Liu H, Chen X et al (2012) Structure of follicle-stimulating hormone in complex with the entire ectodomain of its receptor. PNAS 109(3):1249112496

5. Bassil N, Alkaade S, Morley JE (2009) The benefits and risks of testosterone replacement therapy: a review. Ther Clin Risk Manag 5(3):427-448

6. Mahnaz G, Namdar Y (2015) Impact of morphine dependency and detoxification by methadone on male's rat reproductive system. Iran J Reprod Med 13(5):275-282

7. Osadolor HB and Omo-Erhabor JA; Effects of tramadol on fertility hormones (folliclestimulating hormone, leutinizing hormone, prolactin, testosterone, estrogen and $\beta$-HCG) in laboratory rabbits BJMMR, 14(8): 1-11, 2016; Article no. BJMMR. 24620

8. Daniell PH, Jones AC, Josephs RA (2006) The social endocrinology of dominance: basal testosterone predicts cortisol changes and behavior following victory and defeat. J Personal Soc Psychol 94(6):1078-1093

9. Colameco S, Coren JS, Ciervo CA. 2009: Continuous opioid treatment for chronic noncancer pain: a time for moderation in prescribing. Postgrad Med. Jul 1:121(4):61-66.

10. Wang S, Aurora AB, Johnson BA, Qi X, McAnally J, Hill JA, Richardson JA, Bassel-Duby R, Olson EN. 2008. The endothelial-specific microRNA miR-126 governs vascular integrity and angiogenesis. Dev Cell. Aug 12;15(2):261-271.

11. Reddy RG, Aung T, Karavitaki N, Wass JA. 2010. Lesson of the week: opioid induced hypogonadism. The BMJ.;341.

12. Rajagopal A, Vassilopoulou-Sellin R, Palmer JL, Kaur G, Bruera E. 2010. Symptomatic hypogonadism in male survivors of cancer with chronic exposure to opioids. Cancer. Feb 15;100(4):851-858.

\section{Publisher's Note}

Springer Nature remains neutral with regard to jurisdictional claims in published maps and institutional affiliations.

\section{Submit your manuscript to a SpringerOpen ${ }^{\circ}$ journal and benefit from:}

- Convenient online submission

- Rigorous peer review

- Open access: articles freely available online

High visibility within the field

- Retaining the copyright to your article

Submit your next manuscript at $>$ springeropen.com 